\title{
A predictive nomogram for lymph node metastasis of incidental gallbladder cancer: a SEER population-based study
}

\author{
Yingnan Yang, Zhuolong Tu, Huajie Cai, Bingren Hu, Chentao Ye and Jinfu Tu* (D)
}

\begin{abstract}
Background: Existing imaging techniques have a low ability to detect lymph node metastasis (LNM) of gallbladder cancer (GBC). Gallbladder removal by laparoscopic cholecystectomy can provide pathological information regarding the tumor itself for incidental gallbladder cancer (IGBC). The purpose of this study was to identify the risk factors associated with LNM of IGBC and to establish a nomogram to improve the ability to predict the risk of LNM for IGBC.

Methods: A total of 796 patients diagnosed with stage T1/2 GBC between 2004 and 2015 who underwent surgery and lymph node evaluation were enrolled in this study. We randomly divided the dataset into a training set (70\%) and a validation set (30\%). A logistic regression model was used to construct the nomogram in the training set and then was verified in the validation set. Nomogram performance was quantified with respect to discrimination and calibration.

Results: The rates of LNM in T1a, T1 b and T2 patients were 7, 11.1 and 44.3\%, respectively. Tumor diameter, T stage, and tumor differentiation were independent factors affecting LNM. The C-index and AUC of the training set were $0.718(95 \% \mathrm{Cl}$, 0.676-0.760) and 0.702 (95\% Cl, 0.659-0.702), respectively, demonstrating good prediction performance. The calibration curves showed perfect agreement between the nomogram predictions and actual observations. Decision curve analysis showed that the LNM nomogram was clinically useful when the risk was decided at a possibility threshold of 2-63\%. The Cindex and AUC of the validation set were 0.73 (95\% Cl: 0.665-0.795) and 0.692 (95\% Cl: 0.625-0.759), respectively.
\end{abstract}

Conclusion: The nomogram established in this study has good prediction ability. For patients with IGBC requiring reresection, the model can effectively predict the risk of LNM and make up for the inaccuracy of imaging.

Keywords: SEER, Incidental gallbladder cancer, Nomogram, Lymph node metastasis, Predict

\section{Backgroud}

Gallbladder cancer (GBC) is a rare malignancy. Its annual incidence rate is 2.2 per 100,000 [1]. GBC has no obvious characteristic manifestations at its early stage, so it is difficult to identify early. However, it is highly invasive [2]. Most GBC patients are at an advanced stage once confirmed and lose the opportunity for surgical treatment [3]. Fortunately, with the development of laparoscopy, an increasing number of

\footnotetext{
* Correspondence: tujinfu@sina.com

* Correspondence: tujinfu@sina.com
Department of Hepatobiliary Surgery, First Affiliated Hospital of Wenzhou Medical University, Nanbaixiang street, Ouhai district, Wenzhou, Zhejiang Province, China
}

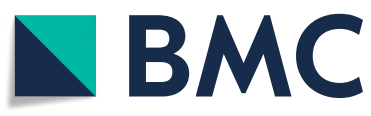

(c) The Author(s). 2020 Open Access This article is licensed under a Creative Commons Attribution 4.0 International License, which permits use, sharing, adaptation, distribution and reproduction in any medium or format, as long as you give appropriate credit to the original author(s) and the source, provide a link to the Creative Commons licence, and indicate if changes were made. The images or other third party material in this article are included in the article's Creative Commons licence, unless indicated otherwise in a credit line to the material. If material is not included in the article's Creative Commons licence and your intended use is not permitted by statutory regulation or exceeds the permitted use, you will need to obtain permission directly from the copyright holder. To view a copy of this licence, visit http://creativecommons.org/licenses/by/4.0/ The Creative Commons Public Domain Dedication waiver (http://creativecommons.org/publicdomain/zero/1.0/) applies to the data made available in this article, unless otherwise stated in a credit line to the data.

GBCs may be confirmed at the early stage through laparoscopic cholecystectomy (LC) so that early R0 resection may be performed; thus, progression of the disease may be avoided, and the overall survival rate may be improved $[4,5]$.

More than $50 \%$ of GBCs are diagnosed by intraoperative or postoperative pathological examination after LC [4] and are considered incidental gallbladder cancer (IGBC), in which stage T1/2 GBCs are the most common [6]. IGBC often requires radical re-resection [5]. Among patients with lymph node metastasis (LNM), lymph node dissection is an important part of radical surgery [7]. Although an increasing number of clinical 
centers emphasize the importance of high-quality lymph node dissection [8-10], a study based on the SEER database showed that the lymph node resection rates for stages T1a, T1b, and T2 GBC were only 33.6, 39.2, and $53.7 \%$, respectively [7], which indicated that preoperative lymph node examination was seriously insufficient. LNM is an independent factor influencing the prognosis of early GBC [11, 12]. Therefore, the preoperative diagnosis of LNM is very important. However, current imaging is still not sensitive enough to identify LNM in the preoperative examination [13]. In lieu of the low incidence rate of $G B C$, there is still no study with a large sample size for predicting the risk factors for LNM in early GBC, and there is no quantified prediction model.

LC makes general pathological information on patients with IGBC available before the patients receive reresection [2]. In recent years, nomograms have been broadly used for preoperative prediction of the risk of LNM and have been proven to be effective [14-16]. Therefore, this study aims to use the pathological and demographic information contained in the SEER database to determine the LNM risk factors for IGBC and to establish a nomogram model for predicting the incidence rate of LNM at the early stage of IGBC before re-resection.

\section{Methods}

\section{Data collection}

The SEER (Surveillance, Epidemiology, and End results) database is currently the largest publicly available cancer database, covering approximately $28 \%$ of the US population [3]. The National Cancer Institute's SEER*Stat software (8.3.6 version) was used to collect data. The inclusion criteria were as follows: (1) site record: C23.9, according to the Third Edition of International Classification of Diseases for Oncology (ICD-O-3); (2) pathological type: adenocarcinoma or squamous cell carcinoma; (3) T stage classified as T1a, T1b, T2 and N stage classified as $\mathrm{N} 0$ and $\mathrm{N} 1$ according to 6th edition AJCC staging system; (4) underwent surgery; (5) at least 1 regional lymph node examined; and (6) no preoperative radiotherapy. After the inclusion, patients were excluded if their information regarding tumor size or tumor differentiation was unknown. We also excluded patients diagnosed with M1 stage, for whom surgery was not suitable [17].

We extracted the demographic and clinicopathologic data of patients with T1/2 GBC from the SEER database for model development and validation, including age, sex, race, tumor size, histology, differentiation, depth of invasion, and number of lymph nodes examined.

The whole dataset from the SEER database was randomly partitioned into a training set and a validation set, which included 70 and $30 \%$ of the dataset, respectively. To let each data has the same chance to be assigned to training set and validation set, a simple random sampling method was used for allocation. Specifically, we installed caret package in $R$ software version 3.6.2, then we loaded the foreign, survival and caret packages. And the last step was to run the packages by specific codes. The codes were attached in our Supplementary Material.

\section{Statistical analysis}

Correlations between the clinicopathological characteristics of patients and LNM were analyzed using Pearson's chi-square test or Fisher exact test when needed. To identify factors that were associated with LNM, binary logistic regression analysis was used for univariate and multivariable analyses. Odds ratios (ORs) were presented with 95\% CIs. Preoperatively available variables were included in the logistic regression analysis. To construct a well-calibrated and discriminative nomogram for predicting LNM, a model was developed in a training set and then validated in the validation set. A logistic regression model was used to construct the nomogram with a backward stepwise procedure. Variables with $P<0.05$ were included in the nomogram.

Nomogram performance was quantified with respect to discrimination and calibration. Discrimination (the ability of a nomogram to separate patients with different lymph node statuses) was quantified by concordance indexes (C-indexes) and the area under the receiver operating characteristic (ROC) curve (AUC). Calibration was assessed graphically by plotting the relationship between the actual (observed) probabilities and predicted probabilities (calibration plot) with the bootstrapping method (1000 replications). Clinical usefulness and net benefit were estimated with decision curve analysis (DCA).

Statistical analyses of correlations between clinicopathological characteristics were conducted using SPSS version 24.0 (IBM, NY, US). The partition of dataset, logistic regression analysis, construction and performance quantification of nomogram and DCA were conducted using $R$ statistical software version 3.6.2. All tests were two-sided, and $P<0.05$ was deemed significant.

\section{Results \\ Demographics and pathological characteristics}

Table 1 summarizes in detail the clinicopathological characteristics of 796 patients diagnosed with stage T1/2 GBC between 2004 and 2015. The LNM rates of T1a, $\mathrm{T} 1 \mathrm{~b}$ and $\mathrm{T} 2 \mathrm{GBC}$ in the total population were $7,11.1$ and $44.3 \%$, respectively. There were 560 patients in the training set: 205 patients with $\mathrm{LNM}(+)$ and 355 patients with $\operatorname{LNM}(-)$. There were 236 patients in the validation set: 88 patients with $\operatorname{LNM}(+)$ and 148 patients with $\operatorname{LNM}(-)$. The degree of tumor differentiation, $T$ staging and tumor diameter were all associated with LNM in both groups $(P<0.05)$. The median number of lymph nodes examined in training set was 2 (IQR: $1-5$ ). 
Table 1 Correlations between clinicopathological characteristics of patients and LNM in the training and validation sets

\begin{tabular}{|c|c|c|c|c|c|c|}
\hline \multirow[t]{2}{*}{ Characteristics } & \multicolumn{3}{|c|}{ Training Cohort } & \multicolumn{3}{|l|}{ Validation set } \\
\hline & LNM- & LNM+ & $P$ value & LNM- & LNM+ & $P$ value \\
\hline Median number of retrieved LN (IQR) & $2(1-5)$ & & / & $2(1-4)$ & & / \\
\hline \multicolumn{7}{|l|}{ Age } \\
\hline$\leq 60$ & $103(29.0 \%)$ & $54(26.3 \%)$ & 0.561 & $40(27.0 \%)$ & $21(23.9 \%)$ & 0.702 \\
\hline$>60$ & $252(71.0 \%)$ & $151(73.7 \%)$ & & $108(73.0 \%)$ & $67(76.1 \%)$ & \\
\hline \multicolumn{7}{|l|}{ Gender } \\
\hline Male & $112(31.5 \%)$ & $52(25.3 \%)$ & 0.121 & $46(31.1 \%)$ & $18(20.5 \%)$ & 0.076 \\
\hline Female & $243(68.5 \%)$ & $153(74.6 \%)$ & & $102(68.9 \%)$ & $70(79.5 \%)$ & \\
\hline \multicolumn{7}{|l|}{ Race } \\
\hline White & 249 (70.1\%) & $157(76.6 \%)$ & 0.214 & $108(73.0 \%)$ & $66(75.0 \%)$ & 0.456 \\
\hline Black & $50(14.1 \%)$ & $20(9.8 \%)$ & & $19(12.8 \%)$ & $14(15.9 \%)$ & \\
\hline Others & $56(15.8 \%)$ & $28(13.7 \%)$ & & $21(14.2 \%)$ & $8(9.1 \%)$ & \\
\hline \multicolumn{7}{|l|}{ Histology } \\
\hline Adenocarcinoma & $346(97.5 \%)$ & $203(99.0 \%)$ & $0.343^{*}$ & 147 (99.3\%) & $88(100.0 \%)$ & $0.999^{*}$ \\
\hline Squamous cell carcinoma & $9(2.5 \%)$ & $2(1.0 \%)$ & & $1(0.7 \%)$ & $0(0.0 \%)$ & \\
\hline \multicolumn{7}{|l|}{ Grade } \\
\hline Well differentiated & $87(24.5 \%)$ & $26(12.7 \%)$ & $<0.001$ & $39(26.4 \%)$ & $11(12.5 \%)$ & 0.008 \\
\hline Moderately differentiated & $181(51.0 \%)$ & $96(46.8 \%)$ & & $71(48.0 \%)$ & $40(45.5 \%)$ & \\
\hline Poorly/un- differentiated & $87(24.5 \%)$ & $83(40.5 \%)$ & & $38(25.7 \%)$ & $37(42.0 \%)$ & \\
\hline \multicolumn{7}{|l|}{ T stage } \\
\hline T1a & $38(10.7 \%)$ & $2(1.0 \%)$ & $<0.001$ & 15 (10.1\%) & $2(2.3 \%)$ & $<0.001$ \\
\hline $\mathrm{T} 1 \mathrm{~b}$ & $75(21.1 \%)$ & $8(3.9 \%)$ & & $29(19.6 \%)$ & $5(5.7 \%)$ & \\
\hline $\mathrm{T} 2$ & $242(68.2 \%)$ & 195 (95.1\%) & & $104(70.3 \%)$ & $81(92.0 \%)$ & \\
\hline \multicolumn{7}{|l|}{ Tumor size } \\
\hline$\leq 1 \mathrm{~cm}$ & $67(18.9 \%)$ & $10(4.9 \%)$ & $<0.001$ & $34(23.0 \%)$ & $5(5.7 \%)$ & 0.005 \\
\hline$>1 \mathrm{~cm}$ & $288(81.1 \%)$ & $195(95.1 \%)$ & & $114(77.0 \%)$ & $21(94.3 \%)$ & \\
\hline
\end{tabular}

LNM lymph node metastasis; IQR interquartile rage; * $P$ value is derived from Fisher's exact test; other $P$ values are derived from Pearson's chi-square test

\section{Factors associated with preoperative LNM}

As shown in Table 2, the logistic regression model was used to further verify the effectiveness of the included factors. Univariate analysis showed that tumors with a diameter $>1 \mathrm{~cm}$, stage $\mathrm{T} 2$, and poor/undifferentiation were closely related to LNM. Multivariate analysis further confirmed that tumors with a diameter $>1 \mathrm{~cm} \quad(\mathrm{OR}=3.628$, 95\% CI: $1.770-7.437)$, stage T2 (OR $=11.104,95 \% \mathrm{CI}$ : 2.590-47.597), and poor/undifferentiation ( $\mathrm{OR}=2.110$, 95\% CI: 1.184-3.762) were independent factors influencing LNM. Based on the OR value, T2 stage was the most correlated, followed by the tumor diameter and then the degree of differentiation. Age, sex, race and pathological pattern were not significantly correlated with LNM.

\section{Nomogram development}

Logistic regression indicated that tumor diameter, $\mathrm{T}$ stage and differentiation degree were independent factors influencing LNM. We included these three variables and constructed a nomogram (Fig. 1). To predict the risk of LNM in more detail, we further subdivided the tumor diameters as follows: $1=$ "d $\leq 1 \mathrm{~cm}$ ", $2=$ "d $\leq 2 \mathrm{~cm}$ ", $3=$ "d $\leq 3 \mathrm{~cm}$ ", $4=$ "d $\leq 4 \mathrm{~cm}$ ", $5=$ "d $\leq 5 \mathrm{~cm}$ ", and $6=$ "d $>5 \mathrm{~cm}$ ".

\section{Validation of the model}

The nomogram demonstrated good accuracy for predicting positive lymph nodes, with a C-index of 0.718 (95\% CI, 0.676-0.760) and an AUC of 0.702 (95\% CI, 0.6590.702). The calibration plot presented good agreement between the bias-corrected prediction and the ideal reference line with an additional 1000 bootstraps (mean absolute error $=0.02$ ) (Fig. 2a, c).

The C-index and AUC of the validation set were 0.73 (95\% CI: 0.665-0.795) and 0.692 (95\% CI: 0.625-0.759), respectively, which revealed good concordance and reliable ability to estimate the status of lymph node involvement. The calibration plot of validation also demonstrated good agreement between the bias-corrected prediction and the ideal reference line with an additional 1000 bootstraps (mean absolute error $=0.035)($ Fig. 2b, d). 
Table 2 Logistic regression analysis of risk factors for LNM in training cohort

\begin{tabular}{|c|c|c|c|c|}
\hline \multirow[t]{2}{*}{ Variable } & \multicolumn{2}{|l|}{ Univariate snalysis } & \multicolumn{2}{|l|}{ Multivariate analysis } \\
\hline & Crude OR(95\%Cl) & $P$ value & Ajusted OR(95\%Cl) & $P$ value \\
\hline \multicolumn{5}{|l|}{ Age } \\
\hline$\leq 60$ & 1.00(reference) & & & \\
\hline$>60$ & $1.143(0.777-1.682)$ & 0.498 & & \\
\hline \multicolumn{5}{|l|}{ Gender } \\
\hline Male & 1.00(reference) & & & \\
\hline Female & 1.356 (0.922-1.995) & 0.122 & & \\
\hline \multicolumn{5}{|l|}{ Race } \\
\hline White & 1.00(reference) & & & \\
\hline Black & $0.634(0.364-1.106)$ & 0.108 & & \\
\hline Others & $0.793(0.483-1.302)$ & 0.359 & & \\
\hline \multicolumn{5}{|l|}{ Histology } \\
\hline Adenocarcinoma & 1.00(reference) & & & \\
\hline Squamous cell carcinoma & $0.379(0.081-1.770)$ & 0.217 & & \\
\hline \multicolumn{5}{|l|}{ Grade } \\
\hline Well differentiated & 1.00(reference) & & 1.00(reference) & \\
\hline Moderately differentiated & $1.775(1.073-2.935)$ & 0.025 & $1.260(0.730-2.177)$ & 0.407 \\
\hline Poorly/un- differentiated & $3.192(1.876-5.431)$ & $<0.001$ & $2.110(1.184-3.762)$ & 0.011 \\
\hline \multicolumn{5}{|l|}{ T stage } \\
\hline T1a & 1.00(reference) & & 1.00(reference) & \\
\hline $\mathrm{T} 1 \mathrm{~b}$ & 2.027 (0.410-10.017) & 0.386 & $1.595(0.316-8.058)$ & 0.572 \\
\hline $\mathrm{T} 2$ & $15.31(3.648-64.255)$ & $<0.001$ & $11.104(2.590-47.597)$ & $<0.001$ \\
\hline \multicolumn{5}{|l|}{ Tumor size } \\
\hline$\leq 1 \mathrm{~cm}$ & 1.00(reference) & & 1.00(reference) & \\
\hline$>1 \mathrm{~cm}$ & 4.536 (2.278-9.034) & $<0.001$ & $3.628(1.770-7.437)$ & $<0.001$ \\
\hline
\end{tabular}

\section{Comparison between different prediction methods}

Comparisons between different prediction methods were conducted by decision curve analysis. The decision curve has the ability to show the clinical usefulness of each method based on a continuum of potential thresholds for LNM risk ( $x$-axis) and the net benefit of using the model to risk stratify patients ( $y$-axis) relative to assuming that no patient will have LNM. Figure 3 reveals that the nomogram provided the largest net benefit across the range of LNM risk compared with the methods using tumor size, differentiation and $\mathrm{T}$-stage alone.

\section{Discussion}

GBC is a highly occult cancer with no obvious clinical manifestations in its early stage [3]. With the development of laparoscopy, an increasing number of stage T1/ 2 IGBCs can be detected via pathological biopsy after LC [6]. For IGBCs, postoperative pathological evaluations need to be completed in combination with imaging for re-resection $[18,19]$.
For patients with LNM, lymphadenectomy is an important part of radical resection, and all positive lymph nodes need to be cleared [20]. Although high-quality lymph node dissection was emphasized, preoperative lymph node examination was seriously insufficient based on the results that the resection rates of $\mathrm{T} 1 \mathrm{a}, \mathrm{T} 1 \mathrm{~b}$, and $\mathrm{T} 2 \mathrm{GBC}$ were only $33.6,39.2$, and $53.7 \%$, respectively, according to this SEER-based study [7]. Although current NCCN guidelines recommend radical surgery for all patients with GBC at stages T1b and above [18], several studies have concluded that patients with $\mathrm{T} 1 \mathrm{~b}$ and $\mathrm{T} 2$ stages might not require radical surgery [21-24]. However, some studies have shown that LNM is closely related to malignant phenotype of early stage GBC $[25,26]$, we believe that patients diagnosed with LNM preoperatively should receive more aggressive surgical treatment and more extensive lymph node dissection than patients without LNM.

$\mathrm{CT}$ is the most commonly used clinical imaging method [27]. Although CT can accurately show the invasion of tumors in blood vessels and adjacent organs, its accuracy for the identification of LNM is very low [28]. 


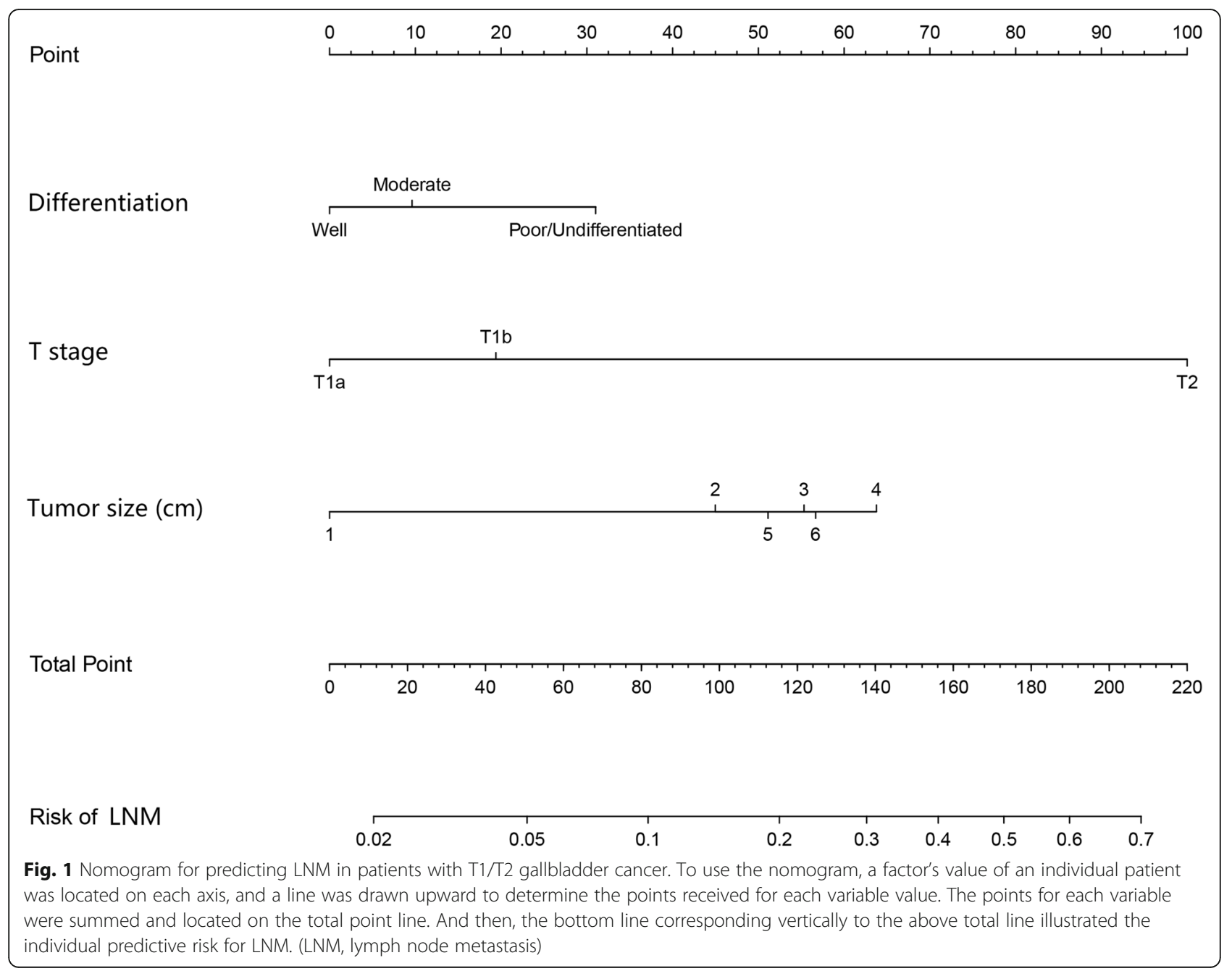

Some studies have shown that more than half of the positive lymph nodes existing among GBC patients cannot be detected by preoperative CT examination [24, 27, 29]. Unfortunately, neither MRI nor PET-CT is a good supplement for CT [28, 30, 31]. The present study may combine clinical imaging to further improve the estimation of the risk of LNM, which is conducive to clinicians choosing the most suitable surgical methods for patients.

Among the cases of GBC included in this study, the LNM rate of stage T1a was $7 \%$, stage T1b was $11.1 \%$, and stage $\mathrm{T} 2$ was $44.3 \%$. For a variety of early primary cancers in the digestive tract, such as gastric cancer [14], appendiceal cancer [15], and colon cancer [16], the SEER database has been used to establish a nomogram for predicting the risk of LNM. In this paper, the SEER database was used to predict the risk of LNM in IGBC and construct a nomogram. In the present study, tumor diameter, tumor differentiation degree and $\mathrm{T}$ stage were independent factors influencing metastasis, of which $\mathrm{T}$ stage was the most significant factor. Compared with that at stage T1a, the risk of LNM at stage T2 may have increased by 11 times. The second most significant factor was tumor diameter. When the tumor diameter was greater than $1 \mathrm{~cm}$, the risk of LNM may have increased by 3.6 times. According to the nomogram, there was little difference in the risk of LNM when the tumor diameter was greater than $1 \mathrm{~cm}$, but the risk was reduced when the tumor diameter was greater than $4 \mathrm{~cm}$. The least significant factor was tumor differentiation. The risk of LNM in poorly differentiated or undifferentiated patients was only twice as high as that in welldifferentiated patients. Gallbladder adenocarcinoma (76-90\%) and squamous cell carcinoma (2-10\%) are the two most common pathological patterns of GBC and the prognosis of squamous cell carcinoma is worse than that of adenocarcinoma [32], but in our study, it is indicated that there was no significant correlation between pathological patterns and LNM. We believe that there are two possibilities: (1) according to the relevant literature, squamous cell carcinoma is more likely to invade the liver than LNM [33], which may further confirm that there is no correlation pathological patterns in LNM; and (2) the number of T1/2 squamous cell carcinomas is too small to be statistically significant. 

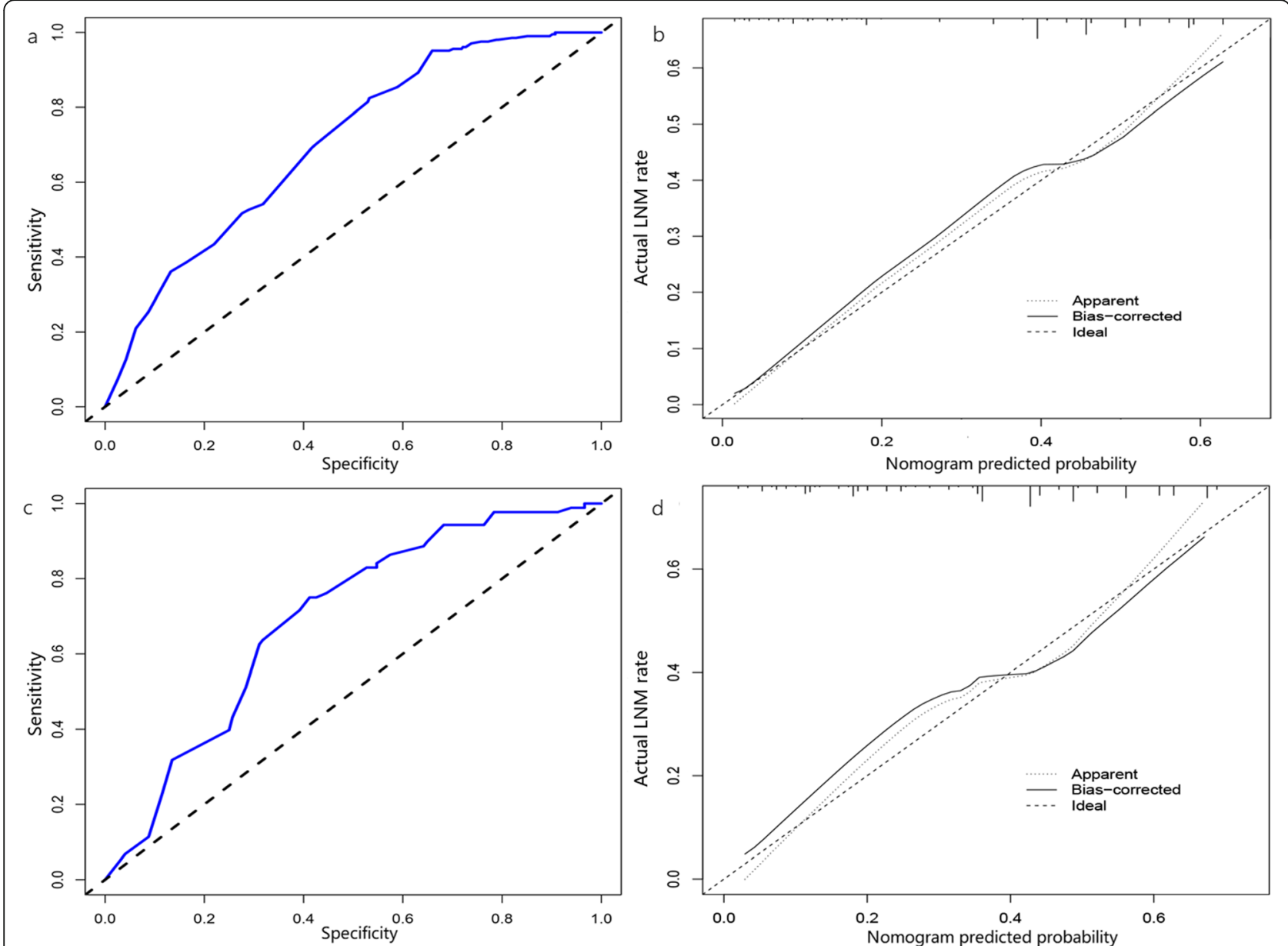

Fig. 2 Discrimination and validation of nomogram for predicting LNM in T1/T2 gallbladder cancer. a and c ROC for discrimination in the training and validation sets. The AUCs of the nomograms were 0.702 (95\% Cl 0.659-0.745) and $0.692(95 \% \mathrm{Cl} 0.625-759)$, respectively. b and $\mathbf{d}$ Calibration plot for the nomogram in the training and validation sets. The $\mathrm{x}$-axis represents the nomogram predicted probabilities as measured by logistic regression analysis, and the $y$-axis represents the actual probabilities. (ROC, receiver operating characteristics; $\mathrm{AUC}$, area under the curve; $95 \% \mathrm{Cl}$, 95\% confidence interval)

Considering the low incidence rate of GBC, few singlecenter studies have previously used clinical data to predict the risk of LNM in early GBC. Therefore, we used DCA to compare the differences in predictive power among the nomogram and the included univariates. According to Fig. 3, the probability thresholds of differentiation, $\mathrm{T}$ stage, tumor size and nomogram are $0.23-0.49,0.03-0.45$, $0.28-0.51$ and $0.02-0.63$, respectively. The curve of T-stage is very close to that of nomogram containing three factors, but the probability threshold of T-stage is smaller than that of nomogram. When the risk is decided at a probability threshold lower than 0.38 , the T-stage curve and the nomogram curve almost overlap which indicates the two prediction models almost have the same net benefit within this range, and both are higher than the reference line. However, when the risk is decided higher than 0.38 , the net benefit of T-stage is not as good as that of the nomogram. A comparison between tumor and differentiation shows that when the risk is decided at a probability threshold of $0.23-0.28$, the net benefits of tumor and differentiation are very close and nearly equal to the reference line; when the probability is decided at a probability threshold of $0.28-0.35$, the net benefits of these two are still very close, but higher than the reference line; when the risk is decided at a probability threshold of 0.35 and 0.4 , the net benefit of differentiation is relatively high; and when the probability is decided higher than 0.4 , the net benefit of tumor size is less than 0 while the differentiation model has a prediction ability higher than that of the tumor model. However, the net benefits of these two models within their probability thresholds are both smaller than that of the nomogram. To sum up, although the univariate models have certain predictive power, DCA shows that the nomogram predicts accurately in a wider range.

For GBC patients accompanied by LNM, existing studies recommend cholecystectomy and lymph node dissection for patients at stage T1a [34], and radical surgery 


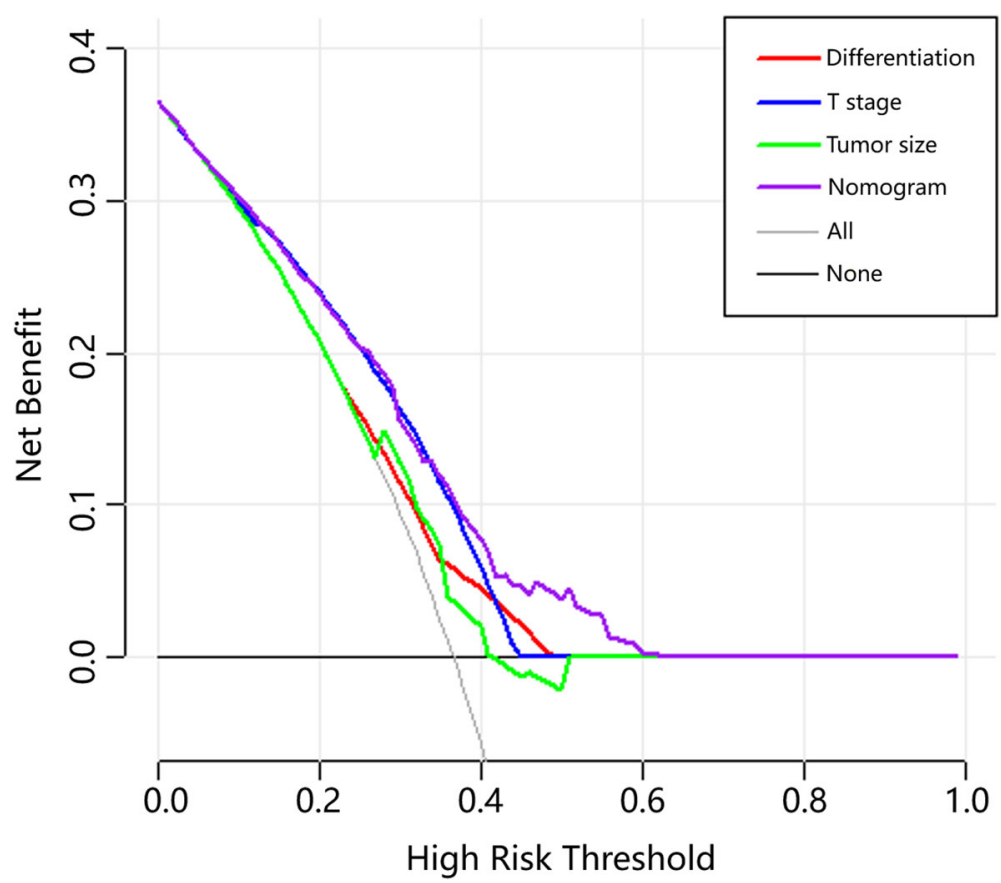

Fig. 3 Decision curve for prediction of LNM for T1/T2 gallbladder cancer. Black line: assume no patient will have LNM; gray line: assume all patients will have LNM; red line: binary decision rule based on tumor differentiation alone; blue line: binary decision rule based on T stage alone; green line: binary decision rule based on tumor size alone; purple line: decision based on nomogram. Probability thresholds for differentiation, $\mathrm{T}$ stage, tumor size and nomogram are $0.23-0.49,0.03-0.45,0.28-0.51,0.02-0.63$, respectively

for patients at stage $\mathrm{T} 1 \mathrm{~b} / \mathrm{T} 2$ [26]. The total score calculated by the nomogram corresponds to the risk of LNM. Zhu et al. [35] put forward that patients with $a \leq 5.0 \%$ predicted risk of LNM are considered as low-risk group, those with $5-15 \%$ predicted risk as intermediate risk group, and those predicted risk $>15 \%$ as high risk group. Combining these conclusions with our study, we assume that patients in low-risk group could choose long-term follow-up, and patients in the high-risk group should be recommended for a re-resection; as for those in intermediate-risk group, patients could choose a longterm follow-up, however, the recommendation of reresection should better be come up with. Take a T1b IGBC patients for example, in clinical practice, if a T1b IGBC patient pathologically diagnosed after LC is with poor compliance to a re-resection, in the meanwhile, no LNM is found by imaging, which is considered having low ability to detect LNM [27, 28, 30, 31], the clinician will be caught into a dilemma that whether a reresection is needed or not. In this case, the clinician may use our nomogram to make a decision. If he/she is pathologically confirmed with a poorly differentiated or undifferentiated tumor with a diameter between 3 and 4 $\mathrm{cm}$, his/her total score will be 113. His/her corresponding risk of LNM is nearly $19 \%$ and is allocated to highrisk group. The clinical suggestion is that him/her should undergo a radical re-resection. In contrast, if the
T1b patient is with a highly differentiated tumor with a diameter less than $1 \mathrm{~cm}$, his/her total score will be 20 , and the risk of LNM is nearly $3 \%$ and is allocated to low-risk group. The clinical suggestion is that he/she could choose to follow up regularly.

We must recognize the limitations that may exist with our study. First, all selected patients have received lymph nodes biopsy and the median number of lymph nodes inspected in training set was 2 (IQR: 1-5), however, the effect of selection bias with $\mathrm{LN}+$ and $\mathrm{LN}$ - due to the non-randomized nature of this study can't be expected. Steffen et al. [7] claimed that retrieval of even a few lymph nodes reliably predicts the lymph node status, which may compensate for this bias. Second, previous studies have concluded that age $<60$, elevated CA199 levels [27], and hepatic-sided tumors [36] can also be used for predicting LNM. However, in this study, age was not necessarily associated with LNM, and this study lacked information concerning the preoperative diagnosis of CA199 and tumor location, which may have led to insufficient influencing factors. Last but not least, the data in SEER database is originated from different sources and hospitals [3], so our study is considered as a multicenter study. However, GBC has regional differences in incidence [37]. Although the nomogram constructed in this study was validated internally and externally having good prediction ability, in our view, 
the generalization ability of the nomogram is still needed to be verified with clinical data other than SEER database. Therefore, we hope that in the future, large sample of GBC patients from different regions can be obtained to construct a nomogram using the three variables selected in this study for further external validation, as well as measurement of the generalization ability of the nomogram.

Despite limitations above, the large-sample based study predicts LNM with good discrimination and calibration both in the training and validation cohorts. The nomogram constructed in this study visualizes the risk factors and could better guide the clinical decisions.

\section{Conclusion}

In conclusion, based on the clinical risk factors identified in a large population-based cohort, we established the first practical nomograms that could objectively and accurately predict the individualized risk of LNM for IGBC patients who required re-resection. Moreover, the validation set results demonstrated that the nomograms performed well and had high accuracy and reliability. Our nomogram was demonstrated to be clinically useful in DCA, and it made up for the inaccuracy of imaging.

Therefore, these results could help clinicians improve individual treatment and make clinical decisions regarding patients with $\mathrm{T} 1 / 2$ stage IGBC.

\section{Supplementary information}

Supplementary information accompanies this paper at https://doi.org/10. 1186/s12885-020-07341-y.

Additional file 1.

\section{Abbreviations}

AJCC: American Joint Committee on Cancer; AUC: area under the receiver

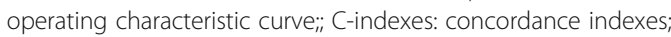
Cl: confidence intervals; DCA: decision curve analysis; GBC: gallbladder cancer; IGBC: incidental gallbladder cancer; IQR: interquartile rage; LC: laparoscopic cholecystectomy; LNM: Iymph node metastasis; OR: odds ratio; ROC: receiver operating characteristic; SEER: Surveillance, Epidemiology, and End results

\section{Acknowledgements}

The authors wish to acknowledge the efforts of the SEER Program tumor registries in the creation of the SEER database.

\section{Authors' contributions}

YNY, ZLT and JFT designed the study and analyzed the data. ZLT and CTY participated in data acquisition. BRH and HJC participated in data interpretation. All authors read and approved the final manuscript.

\section{Funding}

No funding was received.

\section{Availability of data and materials}

The datasets analyzed during the current study are available in the SEER repository (https://seer.cancer.gov/).

\section{Ethics approval and consent to participate}

We received permission from the National Cancer Institute, US to access the research data file in the SEER program (reference number 10013-Nov2019).
Ethics approval was waived by Ethics Committee of First Affiliated Hospital of Wenzhou Medical University, as SEER data is publicly available and without specific identifiers.

\section{Consent for publication}

Not applicable.

\section{Competing interests}

The authors declare that they have no competing interests.

Received: 28 March 2020 Accepted: 25 August 2020

Published online: 31 August 2020

\section{References}

1. Ferlay J, Soerjomataram I, Dikshit R, et al. Cancer incidence and mortality worldwide: sources, methods and major patterns in GLOBOCAN 2012. Int J Cancer. 2015;136(5):E359-86.

2. Hickman L, Contreras C. Gallbladder cancer: diagnosis, surgical management, and adjuvant therapies. Surg Clin North Am. 2019;99(2):337-55.

3. Mao W, Deng F, Wang D, et al. Treatment of advanced gallbladder cancer: a SEER-based study. Cancer Med. 2020;9(1):141-50.

4. Ethun CG, Postlewait LM, Le N, et al. Association of Optimal Time Interval to re-resection for incidental gallbladder Cancer with overall survival: a multiinstitution analysis from the US Extrahepatic biliary malignancy consortium. JAMA Surgery. 2017;152(2):143-9.

5. Galodha S, Saxena R, Singh R, et al. Incidental gallbladder cancer: can we improve survival? Ann Oncol. 2019;30 Suppl 4:iv1.

6. Shih SP, Schulick RD, Cameron JL, et al. Gallbladder cancer: the role of laparoscopy and radical resection. Ann Surg. 2007;245(6):893-901.

7. Steffen T, Ebinger SM, Tarantino I et al. Prognostic Impact of Lymph Node Excision in T1 and T2 Gallbladder Cancer: a Population-Based and Propensity Score-Matched SEER Analysis. J Gastrointest Surg. 2020;24(3):63342.

8. Fan DX, Xu RW, Li YC, et al. Impact of the number of examined lymph nodes on outcomes in patients with lymph node-negative gallbladder carcinoma. World J Gastroenterol. 2018;24(26):2886-92.

9. Ito $\mathrm{H}$, Ito $\mathrm{K}$, D'Angelica $\mathrm{M}$, et al. Accurate staging for gallbladder cancer: implications for surgical therapy and pathological assessment. Ann Surg Oncol. 2011:254(2):320-5.

10. Kim SH, Chong JU, Lim JH, et al. Optimal assessment of lymph node status in gallbladder cancer. Eur J Surg Oncol. 2016:42(2):205-10.

11. Goetze TO, Paolucci V. The prognostic impact of positive lymph nodes in stages T1 to T3 incidental gallbladder carcinoma: results of the German registry. Surg Endosc. 2012;26(5):1382-9.

12. Xiao Z, Shi Z, Hu L, et al. A new nomogram from the SEER database for predicting the prognosis of gallbladder cancer patients after surgery. Ann Transl Med. 2019:7(23):738.

13. de Savornin LE, de Bitter T, van Laarhoven $C$, et al. The diagnostic accuracy of $\mathrm{CT}$ and MRI for the detection of lymph node metastases in gallbladder cancer: a systematic review and meta-analysis. Eur J Radiol. 2019;110:156-62.

14. Mu J, Jia Z, Yao W, et al. Predicting lymph node metastasis in early gastric cancer patients: development and validation of a model. Future Oncol (London, England). 2019;15(31):3609-17.

15. Dan W, Chongshun L, Tingyu Y, et al. A Nomogram for predicting lymph nodal metastases in patients with Appendiceal cancers: an analysis of SEER database. J Investig Surg. 2020. https://doi.org/10.1080/08941939.2019. 171146.

16. Hu DY, Cao B, Li SH, et al. Incidence, risk factors, and a predictive model for lymph node metastasis of submucosal (T1) colon cancer: a populationbased study. J Investig Surg. 2019;20(6):288-93.

17. Wang Z, Li Y, Jiang $W$, et al. Simple cholecystectomy is adequate for patients with T1b gallbladder adenocarcinoma $<1 \mathrm{~cm}$ in diameter. Front Oncol. 2019:9:409.

18. Benson AB, D'Angelica Ml, Abbott DE, et al. NCCN guidelines insights: Hepatobiliary cancers, version 1.2017. J Natl Compr Cancer Netw. 2017:15(5):563-73.

19. Valle JW, Borbath I, Khan SA, et al. Biliary cancer: ESMO clinical practice guidelines for diagnosis, treatment and follow-up. Ann Oncol. 2016;27:v28-37.

20. Sternby Eilard M, Lundgren L, Cahlin C, et al. Surgical treatment for gallbladder cancer - a systematic literature review. Scand J Gastroenterol. 2017;52(5):505-14 
21. Cho JK, Lee W, Jang JY, et al. Validation of the oncologic effect of hepatic resection for T2 gallbladder cancer: a retrospective study. World J Surg Oncol. 2019;17(1):8.

22. Kim DH, Kim SH, Choi GH, et al. Role of cholecystectomy and lymph node dissection in patients with T2 gallbladder cancer. World I Surg. 2013;37(11): 2635-40.

23. Kim HS, Park JW, Kim H, et al. Optimal surgical treatment in patients with T1b gallbladder cancer: an international multicenter study. J Hepatobiliary Pancreat Sci. 2018;25(12):533-43.

24. Lee SE, Jang JY, Lim CS, et al. Systematic review on the surgical treatment for T1 gallbladder cancer. World J Gastroenterol. 2011;17(2):174-80.

25. de Savornin Lohman EAJ, van der Geest LG, de Bitter TJJ et al. Re-resection in incidental gallbladder cancer: Survival and the incidence of residual disease. Ann Surg. 2020;27(4):1132-42.

26. Shibata K, Uchida H, Iwaki K, et al. Lymphatic invasion: an important prognostic factor for stages T1b-T3 gallbladder cancer and an indication for additional radical resection of incidental gallbladder cancer. World J Surg. 2009;33(5):1035-41.

27. Yu TN, Shen B, Meng N, et al. Risk factors of lymphatic metastasis complement poor radiological detection in gallbladder cancer. World J Gastroenterol. 2014;20(1):290-5.

28. Kalra N, Suri S, Gupta R, et al. MDCT in the staging of gallbladder carcinoma. AJR Am J Roentgenol. 2006;186(3):758-62.

29. Petrowsky H, Wildbrett $\mathrm{P}$, Husarik DB, et al. Impact of integrated positron emission tomography and computed tomography on staging and management of gallbladder cancer and cholangiocarcinoma. J Hepatol. 2006;45(1):43-50

30. Corvera CU, Blumgart LH, Akhurst T, et al. 18F-fluorodeoxyglucose positron emission tomography influences management decisions in patients with biliary cancer. J Am Coll Surg. 2004;206(1):57-65.

31. Kim JH, Kim TK, Eun HW, et al. Preoperative evaluation of gallbladder carcinoma: efficacy of combined use of MR imaging, MR cholangiography, and contrast-enhanced dual-phase three-dimensional MR angiography. J Magn Reson Imaging. 2002;16(6):676-84.

32. Samuel S, Mukherjee $\mathrm{S}$, Ammannagari $\mathrm{N}$, et al. Clinicopathological characteristics and outcomes of rare histologic subtypes of gallbladder cancer over two decades: a population-based study. PLoS One. 2018;13(6): e0198809.

33. Kalayarasan $R$, Javed A, Sakhuja $P$, et al. Squamous variant of gallbladder cancer: is it different from adenocarcinoma? Am J Surg. 2013;206(3):380-5.

34. Widmann B, Warschkow $R$, Beutner $U$, et al. Effect of lymphadenectomy in curative gallbladder cancer treatment: a systematic review and metaanalysis. Langenbeck's Arch Surg. 2020;405(5):573-84.

35. Zhu M, Cao B, Li X et al. Risk factors and a predictive nomogram for lymph node metastasis of superficial esophagogastric junction cancer. J Gastroenterol Hepatol. 2020. https://doi.org/10.1111/jgh.15004.

36. Toge K, Sakata J, Hirose Y, et al. Lymphatic spread of T2 gallbladder carcinoma: regional lymphadenectomy is required independent of tumor location. Eur J Surg Oncol. 2019;45(8):1446-52.

37. Aloia $\mathrm{T}$, Jц N, Javle $\mathrm{M}$, et al. Gallbladder cancer: expert consensus statement. HPB (Oxford). 2015;17(8):681-90.

\section{Publisher's Note}

Springer Nature remains neutral with regard to jurisdictional claims in published maps and institutional affiliations.

Ready to submit your research? Choose BMC and benefit from:

- fast, convenient online submission

- thorough peer review by experienced researchers in your field

- rapid publication on acceptance

- support for research data, including large and complex data types

- gold Open Access which fosters wider collaboration and increased citations

- maximum visibility for your research: over $100 \mathrm{M}$ website views per year

At BMC, research is always in progress.

Learn more biomedcentral.com/submissions 